\title{
Problems and Solutions of the GW16 Type Isolation Switch in Operation \\ Zhu Shaohong ${ }^{1}$, Shan $\mathrm{Jia}^{2}$, Yi Yongfei ${ }^{3}$, Zhu Yuanda ${ }^{3}$, Gao Yuan ${ }^{1}$, Zhu Dongyue $^{4}$, Wang Yan ${ }^{1}$, Gao Tiejun ${ }^{1}$, Yu Chenguang ${ }^{1}$, Hou Ling ${ }^{1}$ \\ ${ }^{1}$ Tieling Power Supply Company,Liaoning Electric Power Company Limited,State Grid,China \\ ${ }^{2}$ Fushun Power Supply Company,Liaoning Electric Power Company Limited,State Grid,China \\ ${ }^{3}$ Techniques training center,Liaoning Electric Power Company Limited,State Grid,China \\ ${ }^{4}$ Northeastern University \\ 22181221@qq.com
}

Keywords: isolation switch; solution; over heat; corrosion; jam

\begin{abstract}
GW16 type isolation switch of outdoor high voltage system is the commonly used power distribution equipment in $220 \mathrm{kV}$ power system. And it is widely used in the substations that maintained by the EHV power transmission company of Hunan province. It is mainly composed of a static contact assembly, main switch system, the knife blade, rotation of the insulator and the support insulator, a base assembly and transmission system, operating mechanism. It has the advantages of simple structure, convenient installation and operation, but in the operation also exists some problems, this paper in view of the problems proposed feasible solutions.
\end{abstract}

\section{Problems}

\section{Diversion System Contact Surface Overheating}

1) Static contact heating

The static contact burning, steel core aluminium wire oddlot, plywood, block cracking, bolt loosening, and transition set damage, etc.

2) Conductive system overheating

Disconnecting link is not in place causes the contact point pressure of the moving and static contact is not enough, the contact surface is not smooth, and the silver plating layer is worn or falls off; the connection among the conductive strip, the contact piece and the movable contact seat is not tight, and the contact surface is oxidated; and the conduction band broken seriously, the upper guide tube and the movable contact seat contact surface is oxidated. The rotary contact of the middle joint is heated, the spring is cracked and deformed, the silver layer on the contact finger is damaged, the pressing block is damaged, the connecting base rotating contact assembly is hot; the connection between the lead wire clamp and the connecting base is loose, and the oxidation and etc.

\section{Rotation, Transmission Parts Get Rust}

The operate mode of GW16 type isolation switch is three-phase linkage. The three phases are formed together through connecting rod to form linkage. The mechanism drives the gear screw rod, the screw nut, the shifting fork and the stepless regulation flange plate through the electric motor to make the mechanism slow down, and to transmit the torque to the main shaft of the switch to make it move. Because of the effect of the installation level, the installation verticality of insulator and porcelain support rotation is not up to the requirements, three base are not at the same level, the level of three-phase linkage is not in the same straight line and the rod strength is not enough. Due to high operating torque, the large bevel gear and gear shaft welding of connecting base assembly falling off. The reason is that the adjustment of balance spring which in the under guide pole is not in place, the small compressibility, resulting in knife gate closing operation great torque, composite shaft sleeve crank arm connecting pin shaft corrosion, axial and copper sleeve being hard contacted. After a considerable period of time, the copper sleeve and the spindle get rust, causes the difficulties of rotation. Or the switch is no oil before installation and use, causing sleeve serious wear. 


\section{Insulator Rupture}

The turning porcelain fracture phenomenon is more common, also support porcelain fracture phenomenon. There also exist supporting porcelain fracture phenomenon. The main reason of the turning porcelain fracture is the rust at the rotation and transmission parts of the knife gate, and lubricating oil dry, resulting in operating torque increase greatly, porcelain by the large torque and twist off. The porcelain flange bonding being etched by wind and rain for a long time, and thermal expansion and contraction lead to fall off layer by layer. Such a vicious cycle, finally result in the insulator and the flange completely detachment out of the external force. Another reason is the improper adjustment of the balance spring.

\section{Actuator Fault}

Mainly including mechanical failure and electrical failure. The mechanical failure including the mechanism being locked by grounding switch, and the screw nut can not reset result in the motor idling, etc. The electrical failure including the power circuit is obstruct, the breaker is in the closing state or conversion switch is not in place, the bus switch at both ends of the grounding switch is in the closing state, lead to unreasonable circuit control etc.

\section{Grounding Knife Gate EHV Operation Difficulty}

Before the substation transformed, which is managed by the power transmission company of Hunan province, although a lot of grounding knife switch is single phase operation, it is still difficult. Switch can not be put in place, the vertical transmission rod even being twist off, and the gear of hand-operating mechanism would appear broken teeth. The main reason is that the manually operated mechanism of the grounding knife switch of the isolation switch is eroded by the wind and rain for a long time, and the rotating parts are not tightly sealed. Although being coated with grease, it forms a layer of dry hard layer with the rain, dust, rust and other effects together, the rotation shafts are bonded together, resulting in the difficulty of turning the shaft.

\section{Solution}

\section{The Improvement of the Leading Electrical System}

The respective conductive contact surfaces should be polished smooth, the fixed contact surfaces such as coated conductive paste clips should be coated with conductive paste, so that they can have a good contact; the conductive grease or neutral vaseline which is coating on the dynamic and static contact at the contact should be uniformly thin, otherwise it will stick dye dust easily and affect the contact. Note that when polishing silver layer can not be rubbed off too much of the silver layer and burning off should be re-processed silver.

\section{Increasing the Contact Pressure}

When the switch is in the operation, rain cover become old and damaged, rain come into the internal conductive tube, internal clamping spring, spring pins rust, so that the spring will be reduced, cutting cylindrical pin, causing the movable contacts can not be clamped. Besides since the small wheel in the middle of the connecting fork wear severe deformation, also leads to a reduction of the clamping force. According to experience, the original cylindrical pin replaced within 8 plus a cylindrical pin 5; replacing the entire length of the spring clamp unqualified covers (The free length should be $340-\mathrm{t}-5 \mathrm{~m} / \mathrm{n}$ ); replacing the wheel wear resistant composite wheel, so that it can be better.

\section{The Improvement of Operating Mechanism}

This type of knife was originally equipped with the type of CJ7 electric mechanism, the output shaft drives the rotary action of middle phase insulator by a double four agencies above the box. Since the many intermediate links and a large operating torque, the links always become twist. besides since the original screw nut dish stretch across the switch is not enough, the phenomenon of tripping and can not be reset often appears. We have carried out all the transformation of such institutions, instead CJ7B electric mechanism, increasing the intensity of the spring. After the closing minutes in place, then even if the screw nut separate from the screw can also be automatically reset. In addition, CJ7B electric mechanism main shaft rotated by the output rod drive 
to reduce intermediate links output torque loss and increase reliability.

\section{The Improvement of Ground Switch Hand-operating Mechanism}

Change the original type of CS17-1I hand-operating mechanism institutions to the type of CSB hand-operating mechanism of the base assembly use the patent products of the Changsha high voltage switch gear factory. The rotational parts of the improved new institutions become more flexible. The coupling between the mechanism spindle and the spindle switch use the mode of friction disc, the operating torque of which is large, after the transformation, the three-phase linkage operation of grounding switch mechanism has a smaller force than the original single-phase operation.

\section{References}

[1] Chen Shiqing. On the Condition-based Maintenance of Power Transformer [J]. Transformer.

[2] Lu Jizhi. On the Condition-based Maintenance and Development of Electric Transmission and Transformation Equipment[J ].Yunan Electric Power.

[3] Ma Jie. Carry out Equipment Condition-based Maintenance and Ensure the Safe Operation of Power Grid[J].Sci-Tech Information Development \& Economy.

[4] China Planning Press. Collaboration for the Construction and Acceptance Standard of Installation Project of Electrical Device [M].Beijing:China Planning Press.

[5] Chemistry Standardization for Power Plant Technical Committee of Ministry of Electric Power Industry. Collaboration for the Standards of Quality and Test Method of Oil Used for Electric Power [M]. China Standard Press. 